\title{
Effect of Story-Based Audio Visual Mnemonics in Comparison with Text Reading Method on Memory Consolidation among Medical Students: A randomized Controlled Trial
}

Mona Mohamed Ibrahim Abdalla ( $\square$ monaalbetar@yahoo.com )

International Medical University https://orcid.org/0000-0002-4987-9517

Meram Azzani

MAHSA University College Faculty of Medicine and Biomedical Sciences

Reanugah Rajendren

MAHSA University College Faculty of Medicine and Biomedical Sciences

Tan Kim Hong

MAHSA University College Faculty of Medicine and Biomedical Sciences

Yamunah A/P Balachandran

MAHSA University College Faculty of Medicine and Biomedical Sciences

Toffahah Ruwa Fayyad Mohd Hassan

MAHSA University College Faculty of Medicine and Biomedical Sciences

Tan Yi Wei

MAHSA University College Faculty of Medicine and Biomedical Sciences

Ummu Kulthum Binti Yahaya

MAHSA University College Faculty of Medicine and Biomedical Sciences

\section{Lau Jing En}

MAHSA University College Faculty of Medicine and Biomedical Sciences

\section{Sridhar Ajaykumar}

MAHSA University College Faculty of Medicine and Biomedical Sciences

\section{Rebecca Anak Roger Moore}

MAHSA University College Faculty of Medicine and Biomedical Sciences

Mohammed Hanifa Salman Haja

MAHSA University College Faculty of Medicine and Biomedical Sciences

\section{Research article}

Keywords: semantic, memory consolidation, pharmacology, medical education

Posted Date: April 27th, 2020 
DOI: https://doi.org/10.21203/rs.3.rs-24300/v1

License: (c) (i) This work is licensed under a Creative Commons Attribution 4.0 International License. Read Full License 


\section{Abstract}

Background: Traditional teaching methods via faculty lectures lacked interactivity, as seen with textbased materials. Hence, this research aimed to compare the effectiveness of story-based audio-visual mnemonics and conventional text reading methods on medical students' memory consolidation.

Methods: A single-center, systematic random sampling, single-blinded, controlled study was conducted among 80 medical students in year one. The students were randomly assigned to the text-based (control) or story-based audio-visual mnemonics (intervention). Then, a test was held immediately, consisting of ten multiple-choice questions and ten oral recall keywords based on the topic given. The test was repeated in one week, two weeks, and four weeks later. Both descriptive and inferential statistics were utilized. The mean score difference between the audiovisual mnemonic and control groups was determined using a two-tailed unpaired t-test.

Results: This study found that participants who underwent a story-based audiovisual mnemonics method had statistically significant higher marks in the single-response answer questions compared to participants who undergone a text reading method. The audiovisual group also spent a statistically significant shorter time to recall in the oral recall test in comparison to the control group.

In conclusion, story-based audio-visual mnemonics are more effective in medical student's memory retention compared to the conventional text reading method.

\section{Background}

Memory has two forms; explicit and implicit. Explicit or declarative memory is related to a person's consciousness and is reliant on the hippocampus and other parts of the medial temporal lobes of the brain for its retention (1). On the other hand, implicit memory that is also known as non-declarative memory does not involve awareness, and its retention does not usually rely on the hippocampus. Explicit memory is further classified into episodic memory for events and semantic memory for facts (e.g., words, rules, and language meaning) (2). Semantic memory is also the principle of encoding something into a meaning, contributing to long term memory. Explicit memories required for activities such as riding a bicycle can become implicit once learned (3). The stored items in the short term tend to decay over time (within seconds to hours), short duration. Also, the capacity of this type of storage is limited, and there is a limitation on how many items can be stored into short term memory $(4,5)$. Long term memory, distinctively owns the capacity and duration where items can be stored even for a lifetime. It is more permanent than short term memory, holds limitless storage of all our information learned throughout our lifetime. The main problem arises when humans face difficulties in retrieving information from long term storage- in this case, we all need retrieval cues, and it must be closely match the way the information or particular memory was encoded into long term storage (6). Forgetting is ordinary as human memory is imperfect because the new information that is acquired each day interfere with the previously stored memory (7). A study done by D'Eon MF on course evaluation which measures the loss of knowledge 
among the first-year medical students concluded that there was a substantial amount of knowledge loss among his tested subject and failure of memory retention; storing learning content into long term memory has been identified one of the reasons pertaining knowledge loss (8). According to an assessment of knowledge retention ability of undergraduate medical students of year one MBBS UMDC, Karachi, it has been concluded that memory and knowledge retention play an essential role in medical student's grades. The study has suggested the medical education system should be customized in a way where medical students would be able to store knowledge and whatever been taught into their long term memory, which indirectly achieving effective learning (9). Mnemonics are one of the methods to enhance memory consolidation. Ancient Greeks developed the basic principle of mnemonics (10). There was much modern research done on the mnemonics method illustrates the effectiveness of mnemonics as a powerful tool for memory. (11) Bakken, 2017 stated that mnemonic strategies helped students with intellectual and developmental disabilities to remember important information. Students in all class levels remember factual information two to three times more, and these strategies help them to recall information even after a long time (12). Besides, Mastropieri \& Scruggs gave mnemonic instruction and conventional textbook instruction to seventeen mildly handicapped elementary students who were receiving special education. They found students who received mnemonic instructions performed substantially better than those with conventional textbook instruction (13). Apart from that, a study by Mastropieri-1988 incorporating visual and auditory cues, accompanied with memory-enhancing (keyword) mnemonic method. It has been associated with increased memory retention as learners could convert the visual mnemonics into meaningful information. With this method, even students with disabilities performed well (14) However, medical education still evolved as an instructor-centered model $(15,16)$ that detach students from shaping their educational experiences (17). Traditional teaching methods focussing on passive learning via faculty lectures lacked interactivity, as seen with text-based materials $(18,19)$. For years, medical students are loaded with a tremendous amount of information and reading texts, which leads to stress (20). Hence, this research aimed to investigate the effect of story-based audio-visualmnemonics on medical students' memory consolidation, also to compare the effectiveness of storybased audio-visual mnemonics and conventional text reading method on medical students' memory consolidation.

\section{Methods}

The targeted population in this research was first-year medical students of MAHSA University. A singlecenter, systematic random sampling, subject-blinded, controlled study was conducted to compare the story based audio-visual mnemonic method with the traditional text-based material on memory retention among first-year medical students. Eighty students out of a total of 160 students registered in Year 1 were selected by systemic random sampling. The inclusion criteria were year one medical student, both male and female, and there was no age restriction. The students were randomly assigned to the text-based or story-based audio-visual mnemonics. They were assigned to use two different types of study materials covering selected medical topics from different subjects; Microbiology, Parasitology, and Pharmacology. The students in the audio-visual mnemonic group learned the topics through a story-based audio-visual 
mnemonics tool. Whereas subjects in the control group were given the same topics through reading textbased materials with basic terms highlighted. The students in the control group were allowed to repeat/revise their study material within 30 minutes' duration. Whereas students who were assigned to the audiovisual mnemonic were allowed to revise/view the audiovisual mnemonics (video) twice. A test consisting of ten multiple-choice questions and ten keywords oral recall was held immediately after the session. The test was repeated in one week, two weeks, and four weeks later. The ten multiple-choice questions and ten oral recall questions were prepared from MAHSA MBBS year one previous tutorial and past year exams from each department (Parasitology, Microbiology, and Pharmacology). The time taken for students in group 1 (text-based) and Group 2 (audiovisual) to answer ten oral recall questions were recorded for all three subjects. While for multiple-choice questions, which was a single response answer, one mark was given for each correct answer, and the marks were then added up for each subject, respectively.

\section{Statistical Analysis}

Data were analyzed using SPSS software version 23. Both descriptive and inferential statistic was utilized. Mean, and the standard deviation was reported for numerical variables. Proportions and percentages were reported for categorical variables. Moreover, a two-tailed unpaired t-test was conducted to find out the mean score difference between the audiovisual mnemonic and control groups. P-value of less than 0.05 was considered statistically significant.

\section{Results}

\section{NUMBER OF STUDENTS}

The total number of first-year medical students who agreed to participate in the current study was 79 . Participants were randomly assigned to either the text-reading group or the audio-visual group. Table 1 shows the gender distribution in each group.

Table 1: Gender distribution according to the type of intervention $(n=79)$

\begin{tabular}{lll} 
& Text-reading (\%) & Audiovisual (\%) \\
\hline Gender: & & \\
\hline Male & 20.25 & 21.52 \\
\hline Female & 30.38 & 27.85 \\
\hline Total & 50.63 & 49.37
\end{tabular}

The differences between the two groups in their test scores immediately, one weak, two weeks, and four weeks' intervals after the intervention. 
As shown in Table 2, the audio-visual group scored significantly higher than the text-reading group in the single response answer questions tests conducted immediately, one weak, two weeks, and four weeks after the intervention. It also shows a progressive increase in the difference between the mean total marks between the two groups as the time increases after the intervention. It also shows a marked progressive decrease in the mean score of the text reading group $(16 \%, 24 \%, 39 \%$ decrease after one week, two weeks, and four weeks respectively, as compared with their immediate mean test scores). However, the audio-visual group showed a slight increase in the mean score after one week, followed by a small decrease in the subsequent tests; $2 \%$ after two weeks, $2.5 \%$ decrease after four weeks relative to their immediate test score mean.

Table 2: Total marks of text reading group in comparison to the audio-visual group at different time intervals for three subjects $(n=79)$

\begin{tabular}{lccclcc} 
& & & & & \multicolumn{3}{c}{$\begin{array}{c}95 \% \text { confidence } \\
\text { interval }\end{array}$} \\
\hline Total marks* & Mean & $\begin{array}{l}\text { Standard } \\
\text { deviation }\end{array}$ & $\begin{array}{l}\text { T-test } \\
\text { value }\end{array}$ & $\begin{array}{l}\text { P value } \\
\text { valuer }\end{array}$ & Lower & Upper \\
\hline $\begin{array}{l}\text { Session } \\
\text { 1(immediately) : }\end{array}$ & & & & & & \\
\hline Group 1(text reading) & 24.28 & 2.60 & -2.13 & 0.04 & -2.55 & -0.08 \\
\hline Group 2(audio visual) & 25.59 & 2.90 & & & & \\
\hline
\end{tabular}

Session 2(1 week

after)

$\begin{array}{lllllll}\text { Group 1(text reading) } & 20.18 & 4.05 & -7.81 & 0.00 & -7.12 & -4.22 \\ \text { Group 2(audio visual) } & 25.85 & 2.07 & & & & \end{array}$

Session 3(2 weeks

after)

$\begin{array}{lllllll}\text { Group 1(text reading) } & 18.23 & 3.52 & -10.50 & 0.00 & -8.10 & -5.51 \\ \text { Group 2(audio visual) } & 25.03 & 2.07 & & & & \end{array}$

Session 4(1 month

after)

$\begin{array}{lllllll}\text { Group 1(text reading) } & 14.98 & 6.11 & -9.75 & 0.00 & -12.03 & -7.92 \\ \text { Group 2(audio visual) } & 24.95 & 2.11 & & & & \end{array}$




\section{The time required by the two groups in the oral recall test at different time intervals}

The mean time required for the immediate oral recall test was significantly higher for the audiovisual group as compared with the text reading group for all of the three subjects tested, as shown in Table 3 . However, as the time interval increases after the intervention, the mean time required for oral recall by the audiovisual group was significantly lower than the mean time required by the text-reading group after one week, two weeks, and four weeks for all subjects. With the progression of the time, the mean time required for recall increases for both groups. However, the \% increase in recall time is lower for the audiovisual group as compared with the text reading group.

Table 3: Time required to recall the answer in the different subjects among the two groups in different sessions 
Subject

Microbiology session 1

(Immediately)

Group 1(Text reading)

Group 2(Audio visual)
Mean* Standard

deviation
T-test value
Lower value

Upper

$11.82 \quad 1.38$

$-5.18$

0.00

$-7.24$

$-3.18$

$17.06 \quad 6.13$

\section{Pharmacology session 1 \\ (Immediately)}

Group 1(Text reading)

$12.26 \quad 1.28$

$-3.71$

0.00

$-8.70$

$-2.56$

Group 2(Audiovisual)

$17.89 \quad 9.40$

Parasitology session 1

(Immediately)

Group 1(Text reading)

$8.70 \quad 1.53$

$-3.55$

0.00

$-4.88$

$-1.35$

Group 2( Audio visual)

$11.82 \quad 5.26$

Microbiology session 2 ( 1

week later)

Group 1(Text reading)

$26.20 \quad 1.77$

5.61

0.00

3.37

7.14

Group 2(Audio visual)

$20.94 \quad 5.58$

Pharmacology session 2 (1 week later)

Group 1(Text reading)

Group 2( Audio visual)
$33.23 \quad 4.04$

$19.97 \quad 6.24$
11.18

0.00

10.90

15.64

Parasitology session 2 (1 week later)

$\begin{array}{lllllll}\text { Group 1(Text reading) } & 26.08 & 2.03 & 13.07 & 0.00 & 7.56 & 10.29 \\ \text { Group 2(Audio visual) } & 17.16 & 3.76 & & & & \end{array}$




\section{Microbiology session 3(2}

weeks later)

Group 1(Text reading)

Group 2(Audio visual)
$30.70 \quad 3.44$

$23.68 \quad 5.85$

Pharmacology session 3(2 weeks later)

\begin{tabular}{lllllll} 
Group 1(Text reading) & 36.50 & 6.90 & 9.18 & 0.00 & 11.41 & 17.74 \\
\cline { 1 - 5 } Group 2( Audio visual) & 21.92 & 7.21 & & & &
\end{tabular}

\section{Parasitology session $3(2$ weeks later)}

Group 1(Text reading)

28.59

3.74

5.49

0.00

3.88

8.33

Group 2(Audio visual)

$22.49 \quad 5.88$

\section{Microbiology session 4(1}

month later)

\begin{tabular}{lllllll} 
Group 1(Text reading) & 44.93 & 18.29 & 5.74 & 0.00 & 11.37 & 23.63 \\
\cline { 1 - 5 } Group 2(Audio visual) & 27.43 & 6.00 & & & &
\end{tabular}

Pharmacology session 4(1 month later)

Group 1(Text reading)

$47.77 \quad 21.12$

5.90

0.00

13.61

27.70

Group 2( Audio visual)

$27.12 \quad 6.60$

\section{Parasitology session 4(1} month later)

Group 1(Text reading)

$53.21 \quad 21.84$

7.07

0.00

18.00

32.35

Group 2(Audio visual)

$28.04 \quad 5.40$

*The mean of total time (in seconds) to answer ten questions

\section{Discussion}


This study found that participants who undergone audiovisual mnemonic sessions had statistically significant higher marks in single response answer questions compared to participants who undergone text reading. This study also found that participants who undergone an audiovisual mnemonic method had a statistically significant shorter time required to answer the questions compared to participants who undergone a text reading method. The mean of the total time required to recall all three subjects after seven days, 14 days, and 30 days later by group 2 (Audiovisual group) is lesser, which means the participants in this group had achieved the objective of our study; memory is consolidated.

Participants from the audiovisual group felt this method allowed them to remember complex information to a higher degree and that it was easier to recall answers with picture and story presentation. These results support previous research in 2003 by Rummel N, Levin JR, Woodward MM, where students were randomly assigned to the Pictorial Mnemonics method, and free study also depicts the effectiveness of mnemonics method on students' memory (21). A study on the comparison of interventional education between multimedia textbooks, standard lecture, and printed textbook among third and fourth-year medical students done by M Santer, D. et al. In 1995 illustrated the effectiveness of multimedia-based education, and students scored significantly higher compared to standard lecture and printed textbook group although there was no mnemonics method used (22).

Another study revealed that the use of picture mnemonics into second language vocabulary learning was helpful to teachers and learners while facilitating reading comprehension (23). In 2014, some imagery mnemonics on the porphyrin biochemical pathway were designed and tested on fourth-year medical students of the Icahn School of Medicine at Mount Sinai demonstrated effective results of picture mnemonics usage and increased memory retention. However, the study did not record any recall time (24).

The key behind audiovisual method success is the philosophy of evidence-based learning. Pictures are better than words because audiovisual mnemonics work for improving memory retention; mnemonics help to apply information better through making new terms more meaningful by associating them with something familiar and unforgettable and by organizing information and give it context to improve recall. Audiovisual mnemonics are useful in helping students recall information, and thereby possibly reducing stress and freeing up more cognitive resources for higher-order thinking. In times of stress, it may become even harder to access or recall information explaining why there are many mnemonics in safety situations in which remembering key information with accuracy and speed can be critical (25).

In our study, the time required to recall the keywords for the audiovisual mnemonics group is shorter than the text reading group. Proportional to the study based learning. When we read the text without pictures, it will be stored in the long term memory in a single code. On the other hand, audiovisual mnemonics contains two codes; visual and verbal. Each of them is stored in the different parts of the brain. This dualcoding nature of images allows the brain to access the visual memory in two independent ways. These characteristics increase the odds of remembering at least one of them. Therefore, the time taken to retrieve the memory is shorter among the audio-visual group even after 30 days (26). According to (Harp 
and Meyer), we do not remember the decorative images as well as we do in the informative ones (27) mainly because we remember actual words better than abstract ones as the information will be scattered and difficult to recall. Therefore, to achieve a shorter and faster recall time, we should use words, pictures, and audio together in learning. Visual and verbal memories are stored separately in humans' brains, leads to memory retention. Hence it justifies our results, where Audio-visual mnemonics provide better performance among students (28). According to Moreno and Mayer (2002), students who read while listening to the text learned the material better than those who only listened. The same goes for the student's text, accompanied by animations (29).

\section{Conclusions}

Story-based audiovisual mnemonics is more effective than the conventional text-reading method on medical student's memory retention. Semantic (meaning) correlation is proven as the principle of long term memory. Hence 'story-based audio-visual mnemonic could be introduced as an additional tool/teaching method to improve medical students' memory retention of basic medical sciences.

\section{Declarations}

\section{Ethics and consent to participate}

Written ethical approval was obtained from the Research Management Centre at MAHSA University (approval Number, RMC/EC49/2019) and written informed consent obtained from all subjects when they were enrolled.

\section{Consent for publication}

Not applicable

\section{Authors Contributions}

MA contributed to the study design, literature search, writing of the background, results and discussion, preparation of the manuscript for submission, RR contributed to the study design, analysis and writing of the methodology and background, MA, contributed in study design, writing, data collection, and analysis, TH contributed to writing and data collection, YB contributed to writing and data collection, TB contributed to writing and data collection, TW contributed to the writing and data collection, UY contributed to writing and data collection, LE contributed to writing and data collection, SA contributed to writing and data collection, RR contributed to writing and data collection, HS contributed to writing and data collection. All authors read and approved the final manuscript.

\section{Competing Interests}

The authors declare that they have no competing interests. 
Availability of data and materials

All data generated or analysed during this study are included in this published article

\section{References}

(1) Camina E, Güell F. The neuroanatomical, neurophysiological and psychological basis of memory: Current models and their origins. Frontiers in pharmacology 2017;8:438.

(2) Boron WF, Boulpaep EL. Medical physiology, 2e updated edition e-book: with student consult online access. : Elsevier health sciences; 2012.

(3) Zillmer E, Spiers M, Culbertson W. Principles of neuropsychology. : Nelson Education; 2007.

(4) Barrett K, Barman S, Boitano S, Brooks H. Ganong's review of medical physiology, ed 23, New York, 2009.

(5) Cowan N. What are the differences between long-term, short-term, and working memory? Prog Brain Res 2008;169:323-338.

(6) Baddeley A. Working memory. Science 1992 Jan 31;255(5044):556-559.

(7) Johnson MK, Raye CL, Mitchell KJ, Ankudowich E. The cognitive neuroscience of true and false memories. True and false recovered memories: Springer; 2012. p. 15-52.

(8) Marcel FD. Knowledge loss of medical students on first year basic science courses at the University of Saskatchewan. BMC medical education 2006;6(1):5.

(9) Qureshi FM, Azeem MA, Ejaz M, Marvi M, Soomro S, Hasina L, et al. Assessment of Knowledge Retention Ability of Undergraduate Medical Students. JOURNAL OF THE LIAQUAT UNIVERSITY OF MEDICAL AND HEALTH SCIENCES 2017;16(2):126-130.

(10) Yates FA. Art of Memory. : Routledge; 2013.

(11) Bower GH. Analysis of a mnemonic device: Modern psychology uncovers the powerful components of an ancient system for improving memory. Am Sci 1970;58(5):496-510.

(12) Bakken JP. Mnemonic Strategies: Helping students with intellectual and developmental disabilities remember important information. Global Journal of Intellectual \& Developmental Disabilities.-Vol.2, Iss 2 2017:1.

(13) Mastropieri MA, Scruggs TE. Mnemonic social studies instruction: Classroom applications. Remedial and Special Education 1989;10(3):40-46.

(14) Mastropieri MA. Using the keyboard method. Teaching exceptional children 1988;20(2):4-8. 
(15) Gunderman RB. Achieving excellence in medical education. : Springer Science \& Business Media; 2007.

(16) Irby DM, Cooke M, O'Brien BC. Calls for reform of medical education by the Carnegie Foundation for the Advancement of Teaching: 1910 and 2010. Academic Medicine 2010;85(2):220-227.

(17) Marcel F, Harris C. If students are not customers, what are they? Academic Medicine 2000;75(12):1173-1177.

(18) GRUNDMAN JA, WIGTON RS, NICKOL D. A controlled trial of an interactive, web-based virtual reality program for teaching physical diagnosis skills to medical students. Academic Medicine 2000;75(10):S47S49.

(19) Piemme TE. Computer-assisted learning and evaluation in medicine. JAMA 1988;260(3):367-372.

(20) Augustin M. How to learn effectively in medical school: test yourself, learn actively, and repeat in intervals. Yale J Biol Med 2014 Jun 6;87(2):207-212.

(21) Rummel N, Levin JR, Woodward MM. Do pictorial mnemonic text-learning aids give students something worth writing about? J Educ Psychol 2003;95(2):327.

(22) Santer DM, Michaelsen VE, Erkonen WE, Winter RJ, Woodhead JC, Gilmer JS, et al. A comparison of educational interventions: multimedia textbook, standard lecture, and printed textbook. Arch Pediatr Adolesc Med 1995;149(3):297-302.

(23) Cohen AD. The use of verbal and imagery mnemonics in second-language vocabulary learning. Studies in second language acquisition 1987;9(1):43-61.

(24) de Moll EH, Routt E, Heinecke G, Tsui C, Levitt J. The use of an imagery mnemonic to teach the porphyrin biochemical pathway. Dermatology online journal 2015;21(4).

(25) Making statistics memorable: New mnemonics and motivations. Contributed paper presented for the Section on Statistical Education at the 2011 Joint Statistical Meetings, Miami Beach, Florida; 2011.

(26) Paivio A. Mental representations: A dual coding approach. : Oxford University Press; 1990.

(27) Harp SF, Mayer RE. The role of interest in learning from scientific text and illustrations: On the distinction between emotional interest and cognitive interest. J Educ Psychol 1997;89(1):92.

(28) Mayer RE. Multimedia learning. Psychology of learning and motivation: Elsevier; 2002. p. 85-139.

(29) Moreno R, Mayer RE. Verbal redundancy in multimedia learning: When reading helps listening. J Educ Psychol 2002;94(1):156. 